\title{
Uso de vapor saturado para a produção de fertilizante de descarte de couro bovino com ênfase no impacto ambiental e energético
}

\author{
Elizete Maria Possamai Ribeiro, Dr ${ }^{\mathrm{a}}$ \\ elizete@netvale.net \\ Escola Agrotécnica Federal Sombrio - EAFS \\ Pedro Barbosa Mello, Dr \\ mello@mecanica.ufrgs.br \\ Universidade Federal do Rio Grande do Sul - UFRGS
}

\begin{abstract}
Este artigo tem como objetivo a produção do adubo do couro bovino associado ao resíduo da raspa do couro proveniente da máquina rebaixadeira, com a viabilidade de ganhos ambientais e energéticos. A metodologia foi implantada a partir de revisão bibliográfica sobre as alternativas para o gerenciamento de resíduo sólido da indústria de beneficiamento do couro e do estudo do efeito do cromo no meio ambiente. Para a execução da parte experimental, foi montado um protótipo composto de três equipamentos: caldeira, autoclave e secador. Após a montagem, realizou-se a produção do adubo, considerando-se os parâmetros termodinâmicos: temperatura de 403 a $433 \mathrm{~K}$ e a pressão de 700 a $800 \mathrm{kPa}$. As amostras foram analisadas para verificar os teores dos macros e micronutrientes. Através da reciclagem pode-se afirmar que a produção desse adubo trará vários benefícios, dentre eles a degradação dos resíduos sólidos das indústrias de beneficiamento do couro que deixará de intensificar a poluição ambiental.
\end{abstract}

Palavras-chave: Resíduo; Processo produtivo; Aproveitamento energético e ambiental.

The purpose of this study is to analyze the production of fertilizer from the residue of cattle-leather shavings from Shaving Machine, to offer environmental and energy gains. The methodology was based on a review of bibliographic material of the alternatives for management of solid waste from the leather industry and on a study of the effect of chrome on the environment. For the installation of the experimental portion of the study, a prototype was assembled composed of three pieces of equipment: a boiler, an autoclave and a dryer. After assemblage, production of fertilizer. In relation to the thermodynamic process. The samples were analyzed to verify the levels of the macro and micro-nutrients. The recycling process used in the production of this fertilizer provides various benefits, because the degradation of the solid waste created by the leather industry will no longer intensify the environmental pollution.

Keywords: Solid waste; Productive process; Energetic and Environmental use.

\section{Introdução}

Curtir couros e peles é uma das atividades mais antigas da humanidade. Tudo começou quando o homem primitivo percebeu que um animal não era apenas alimento. Os nossos antecessores préhistóricos utilizavam os couros e as peles de grandes mamíferos para produzir roupas que os protegiam das condições climáticas adversas. Contudo, sem tratamento, o couro ou a pele de um animal rapidamente se deteriora, apodrecendo e exalando um cheiro desagradável.

O couro é normalmente curtido com cromo III. Esse processo visa à obtenção de um melhor acabamento e a um aumento de resistência ao desgaste. Curtir peles com sais de crómio torna-as mais flexíveis e macias, podendo ser tingidas com uma grande variedade de cores. Outros produtos usados para curtir couro são o tanino (produto de origem vegetal), sais de alumínio e zircônio.

O lançamento indiscriminado de resíduo sólido sem tratamento no ambiente implica em problemas ambientais e desperdício de energia. Normalmente, a gestão e o gerenciamento de resíduo sólido industrial no Brasil são caracterizados pelos seguintes aspectos: falta de estudos aprofundados sobre o tema; quantidade e qualidade do resíduo gerado assumem importância considerável no processo de degradação do ambiente; em algumas regiões não há oferta de unidades de tratamento e destinação 
final compatíveis com o grau de industrialização, ocasionando o lançamento inadequado de resíduo no ambiente (SCHNEIDER; BETTIN; PARISE JUNIOR, 2000).

O problema ambiental das emissões do biogás em nível global está se tornando cada vez mais preocupante. As medidas mais recentes mostram que a concentração de metano na atmosfera cresceu fortemente nos últimos anos.

\section{Resíduos Sólidos de Indústria de Curtume}

Shen (1995) afirma que a poluição existe devido à capacidade limitada de absorção pelo ambiente de algumas substâncias que são denominadas poluentes perigosos devido às suas características e ao fato de o ambiente não possuir capacidade para assimilá-los. Observa, ainda, que outras substâncias reconhecidas como degradáveis, ou não perigosas, possuem um limite crítico, acima do qual não podem mais ser assimiladas também.

De acordo com o mesmo autor, nos últimos trinta anos, reconheceu-se a seriedade dos problemas ambientais e, mesmo buscando controlar a poluição, apenas se iniciou a compreensão de sua complexidade. A estratégia de gestão ambiental, no passado, baseou-se no controle da poluição industrial, através de técnicas de coleta, tratamento e destinação final de resíduo. Estas técnicas melhoraram a qualidade ambiental até certo ponto, mas, em geral, não conseguem eliminar as substâncias poluidoras, apenas transferem os poluentes de um meio para o outro. Os processos de tratamento de resíduo produzem uma grande quantidade de lodo e de rejeito que necessitam de tratamento para não se constituírem em poluição secundária. A situação descrita torna evidente que uma solução mais eficiente e eficaz para os problemas de poluição necessita de um outro tipo de abordagem. Assim, nasceu o conceito de prevenção da poluição.

O Brasil se destaca como um dos principais produtores de peles do mundo, tendo aproximadamente 545 indústrias de curtumes produzindo couros dos mais variados tipos. Os principais rebanhos são: bovino, caprino, ovino e suíno. O rebanho bovino é de aproximadamente 165 milhões de cabeças, com uma taxa de desfrute de 16,35\%, resultando em um abate anual de aproximadamente 27 milhões de cabeças (ABQTIC, 1996).

O método de curtimento de peles mais empregado mundialmente é o que utiliza sais de cromo, acarretando a geração de resíduos com a presença deste metal pesado (GUTTERRES, 1996). No Brasil, em 1993, o processo de curtimento gerou cerca de 54 mil toneladas de resíduos contendo sal de cromo. Dentre os principais resíduos sólidos da indústria de curtume contendo cromo, o farelo da rebaixadeira e o pó da lixadeira constituem-se como a principal fonte contaminadora do solo, devido à sua disposição inadequada, conforme pode ser observado na Tabela 1 (SPIER; WESTHAUSE, 1994).

Tabela 1 - Quantidade de resíduo gerado na indústria de curtume (Fonte: CLASS E MAIA, 1994)

\begin{tabular}{l||c}
\hline Resíduo Gerado & kg resíduo por tonelada \\
\hline Aparas caleadas e não caleadas & 120 \\
Carnaças & 150 \\
Aparas curtidas ao cromo & 115 \\
Farelo da rebaixadeira & 175 \\
Pó da lixadeira & 7,5 \\
Aparas de couro acabado & 32 \\
\hline Lodo da ETE & 350 \\
\hline
\end{tabular}

De acordo com a Tabela 1, o farelo da rebaixadeira e o pó da lixadeira geram aproximadamente 182,5 kg de resíduo por tonelada de pele in natura processada.

Por meio destes dados, constata-se que a geração de resíduos sólidos contendo cromo é significativa no setor industrial de curtumes. De acordo com o abate anual do rebanho bovino e reconsiderando a 
média de resíduos de couro da máquina de rebaixar e lixar/desempoar, são gerados no Brasil aproximadamente 123.187,5 toneladas por ano (ABQTIC, 1996; CLASS; MAIA, 1994).

Conforme Germann (1985), nas indústrias de curtumes os resíduos sólidos apresentam problemas de gerenciamento, ou seja, tem havido dificuldade em efetuar remoção dos resíduos da área industrial e também de se encontrar um local adequado para sua disposição. Ainda hoje, as indústrias de curtumes encontram problemas para gerenciar seus resíduos sólidos, sendo sempre consideradas um aspecto muito visado e controlado por órgãos fiscalizadores no Brasil.

\section{Processo Produtivo}

Foi elaborado um protótipo em parceria da empresa JGB e UFRGS - PROMEC para a produção de adubo orgânico de resíduo de couro bovino com os retalhos e o pó da rebaixadeira. As preocupações neste protótipo referem-se à Qualidade Ambiental, pois não se restringem apenas à área ocupacional dos equipamentos, mas também em controlar os impactos produzidos. A indústria JGB, com o aproveitamento dos resíduos gerados, terá vantagem tanto econômica quanto ambiental, pois paga para retirar e colocar em aterros responsáveis este subproduto, como também deixará de emitir $\mathrm{CO}_{2}$ para a atmosfera. A Figura 1 mostra como o protótipo foi montado no seguinte fluxograma:

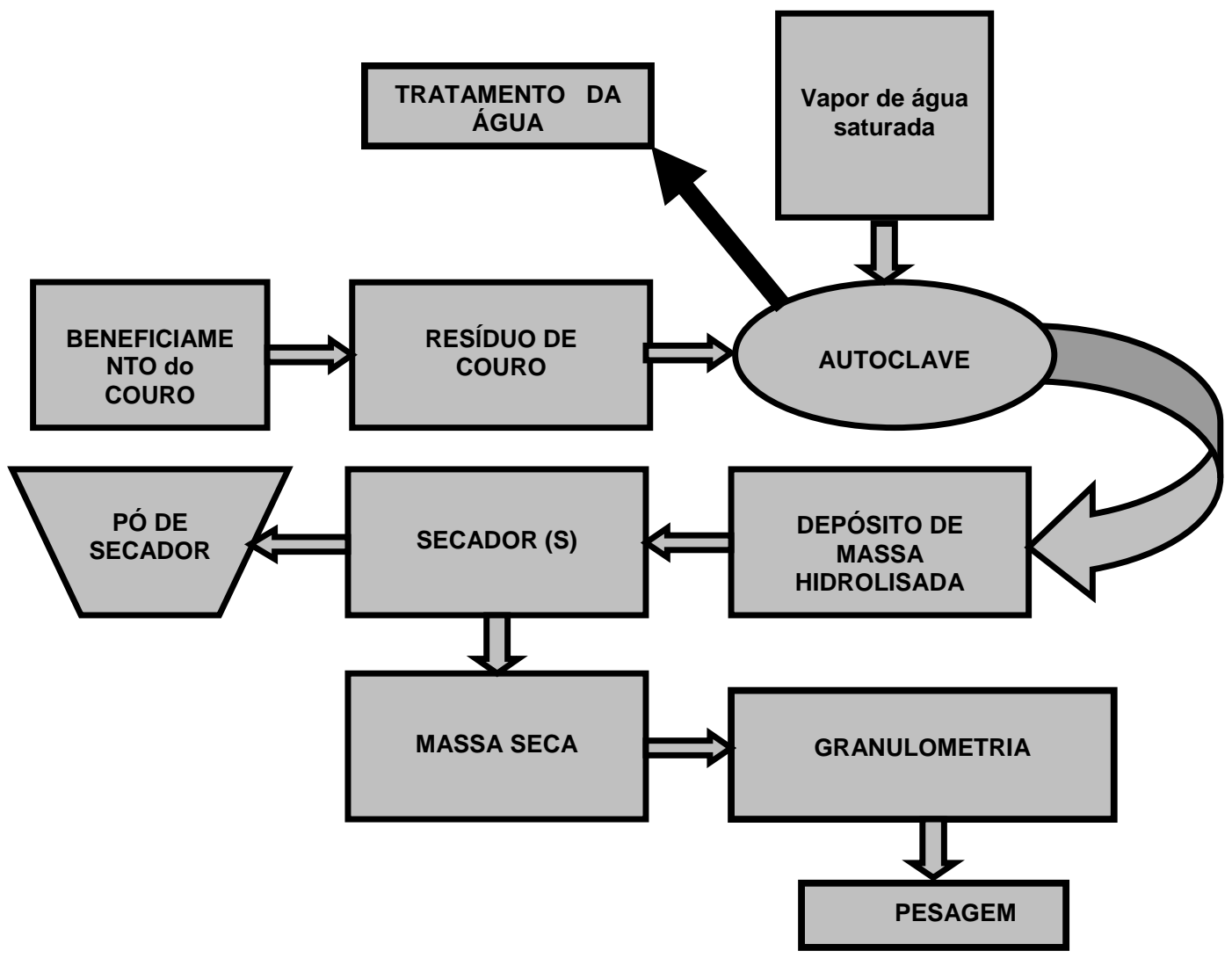

Figura 1 - Fluxograma do processo produtivo do adubo do couro bovino. Compilado pelo autor, 2006.

\subsection{Gerador de Vapor}

Primeiramente foi feita uma revisão bibliográfica com o objetivo de verificar os aspectos relativos aos combustíveis: custos, agressão ao meio ambiente e produção de energia.

Compararam-se dados da queima do óleo e da lenha como combustíveis das caldeiras, sendo a caldeira a óleo da marca APA e a caldeira a lenha da marca CHAMAS, ambas com capacidade de produção de vapor de $2500 \mathrm{~kg} /$ hora, regime de trabalho de 400 horas/mês e pressão de trabalho de $10 \mathrm{kgf} / \mathrm{cm}^{2}$. 
A preocupação na questão ambiental foi referente à fumaça produzida pela caldeira: qual seria a menos poluente, a caldeira a óleo ou a caldeira a lenha? Conforme Caetano e Duarte (2004), a presença de fuligem, que são partículas de combustível não completamente queimadas nos gases de exaustão, acumuladas em superfícies de troca de calor, é mais intensa na queima do óleo combustível. Com relação ao consumo de combustível, a caldeira a óleo consome, em média, 76,50 kg/hora do óleo combustível B.P.F. e a caldeira a lenha, um $\mathrm{m}^{3}$ de lenha/hora ou $620 \mathrm{~kg}$ de lenha/hora. O custo médio do óleo pago pela empresa no período do estudo foi de $\mathrm{R} \$ 0,895 / \mathrm{kg}$, com um custo/hora de $\mathrm{R} \$ 68,46$, implicando em uma despesa mensal de R\$27.384,00. Já o valor pago pela lenha (eucalipto) ficou em torno de R \$ 35,00/m3, com um custo hora de R \$ 35,00. Neste caso, o custo operacional adicional da empresa, relativo à mão-de-obra para transporte da lenha e alimentação da fornalha gira em torno de R \$ 1.500,00/mês, já incluídos todos os encargos, inferindo para a lenha, um custo mensal de R\$ 15.500,00. Nota-se que, apesar de o óleo BPF ter um poder calorífico superior ao da lenha, o primeiro representa maior custo operacional para a empresa.

Tendo em vista os dados aqui apresentados, foi comprada e montada a caldeira a lenha da marca H.BREMER, modelo do gerador de vapor HGV - 20, de pressão de trabalho $8 \mathrm{Kgf} / \mathrm{cm} 2$, e de produção de vapor saturado de $360 \mathrm{Kg}$ /hora e com temperatura do vapor saturado $174,6{ }^{\circ} \mathrm{C}$. Da literatura pode-se concluir que a lenha representa, hoje, combustível de maior viabilidade econômica e ambiental que o óleo combustível.

A lenha utilizada na caldeira para a produção do adubo do couro bovino hidrolisado é a madeira picada, com tamanhos adequados para serem queimados ou transformados em carvão. Utilizou-se a lenha como sendo a madeira de eucalipto (Eucalipto Grandis) seca ao ar, com teor de umidade de $20 \%$, pois, dependendo do tempo de corte, apresenta umidade que varia de 20 a $50 \%$. A lenha, após dois meses de corte e devidamente armazenada, apresenta um teor médio de $35 \%$ de umidade e, após seis meses, um teor médio de $20 \%$ de umidade. A lenha, como gerador de energia renovável, apresenta em sua composição elementar carbono, hidrogênio, oxigênio, nitrogênio e quantidade variável de água.

Para a produção do adubo de couro bovino hidrolisado teve-se um consumo de $45 \mathrm{~cm}^{3}$ de lenha/hora no valor de R \$ 0,002, com uma pressão $8 \mathrm{Kgf} / \mathrm{cm} 2$, com $100 \mathrm{~kg}$ de vapor por hora, com um consumo de energia de aproximadamente $30 \mathrm{KWh}$ com um motor $\mathrm{Hp}-1 \mathrm{CV}$, com R\$ 0,30 por hora para o abastecimento da caixa de água.

\subsection{Autoclave}

O cozimento do couro em autoclave serve para aumentar a disponibilidade de nitrogênio para plantas. Depois de estar desmanchado o resíduo do couro, o nitrogênio orgânico é mineralizado. Isto também é necessário porque as peles de animais, especialmente as de curtumes, são resistentes ao ataque e à decomposição dos microorganismos. Após a fabricação e montagem da autoclave, foi iniciado o processo de produção do adubo baseado no couro bovino curtido ao cromo III. Isso envolve levar matéria-prima à temperatura de $160^{\circ} \mathrm{C}$ por minuto. Os materiais usados no processo de produção do adubo vêm de couro curtido e consistem basicamente de raspagens ou pó da rebaixadeira.

A autoclave serve para hidrolisar a matéria prima, pois o processo do couro hidrolisado desnatura as proteínas (em particular, colágeno). A hidrólise do couro em autoclave serve para aumentar a disponibilidade de nitrogênio para plantas. Depois de hidrolisado, o nitrogênio orgânico é mineralizado. Isto também é necessário porque as peles de animais, especialmente as de curtumes, são resistentes ao ataque e à decomposição dos microorganismos. Com este objetivo foi montada a autoclave.

Carrega-se, a autoclave é hermeticamente lacrada com um bastão de ferro, e nela é introduzido gradativamente o vapor saturado. No decorrer desse processo, automaticamente controlado, a desnaturação das moléculas ocorre sem nenhuma adição de enzimas hidrolíticas ou quaisquer outras substâncias catalisantes. 
O produto obtido, uma massa gelatinosa e de cor escura, é colocado ao sol para desidratar até o material úmido ficar em $12 \%$.

Posteriormente, calcula-se o custo do adubo. Considerando-se que foram gastos $13 \mathrm{Kg}$ de pó de couro bovino da rebaixadeira, em média $10 \mathrm{Kg}$ de vapor por minuto e aproximadamente $15 \mathrm{KWh}$ de energia, corresponde a R\$ 0,15 por hora, com um motor $\mathrm{Hp}-1 / 3 \mathrm{CV}$.

Procedimento de secagem do adubo:

\subsection{Secador}

O secador no processo produtivo tem a função de secar a massa gelatinosa. Foi montado com uma chapa de aço de carbono de $12 \mathrm{~mm}$ de espessura e apresenta um tubo de aproximadamente 6 metros de comprimento e com 33 cm de diâmetro.

Usando uma pá, pratos e baldes, é recolhido o material que está exposto ao sol e colocado em uma máquina para picar. Logo após, é peneirado e separado o pó do grão para facilitar a secagem e é introduzido no secador manualmente com auxílio de um funil (Figura 2). A desidratação ocorre a uma temperatura variando de $100^{\circ} \mathrm{C}$ a $105^{\circ} \mathrm{C}$. Este processo é repetido em média 4 a 7 vezes, dependendo da espessura do grão, até ficarem desidratados.

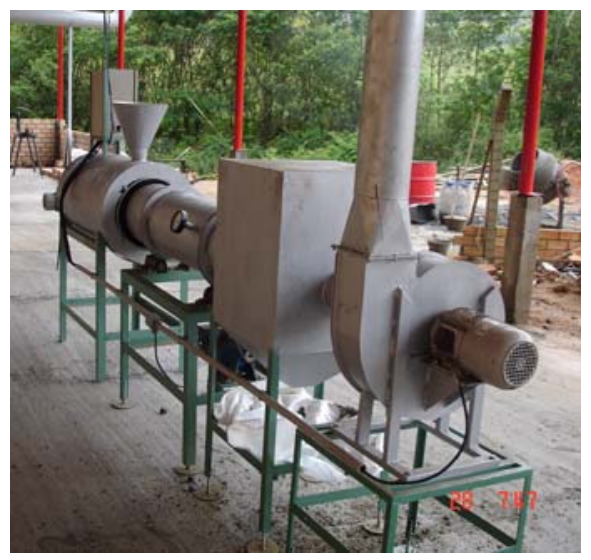

Figura 2 - O secador do adubo do couro bovino hidrolisado. Compilado pelo autor, 2006.

Em seguida, o produto seco é juntado por uma bandeja e exposto ao ar livre para o resfriamento. Após esfriar, o produto é passado novamente por 6 peneiras, onde é separado de acordo com a granulometria. Para fazer a secagem de $282 \mathrm{Kg}$ de massa úmida, gastaram-se em média 5 botijões de gás butano de $30 \mathrm{Kg}$, no valor montante de $\mathrm{R} \$ 190,00$.

\section{Características químicas}

Os resultados das análises do adubo realizadas pelo Instituto Agronômico - Campinas, 2005, estão apresentados na Tabela 2.

O método utilizado para análise dos metais foi o método SW 3051, EPA - U.S., determinação por Espectrometria de Emissão Atômica o ICP - AES (Inductively Coupled Plasma - Atomic Emission Spectroscopy); para nitrogênio total: Kjeldahl; nitrogênio amoniacal: destilação por arraste a vapor; umidade e sólidos voláteis: perda de massa a 333 K e 773 K, respectivamente; carbono orgânico: digestão com dicromato; fluoreto: fusão com soda e determinação com eletrodo íon seletivo. Todos os valores de concentração são dados com base peso seco. As análises foram realizadas em duplicata, devido ao alto custo das análises conforme Tabelas 2 e 3 . Os resultados das análises na Tabela 2 estão especificados em média aritmética. 
Tabela 2 - Características químicas do adubo (Fonte: Análise do adubo do couro bovino - Instituto Agronômico

\begin{tabular}{|c|c|c|}
\hline Parâmetros & Unidades & Média + Desvio Padrão \\
\hline $\mathrm{pH}$ & & $3,45 \pm 0,05$ \\
\hline Umidade & $\%(\mathrm{~m} / \mathrm{m})$ & $4,7 \pm 2,8$ \\
\hline С.T.C & $\mathrm{mmol} / \mathrm{kg}$ & $386 \pm 386$ \\
\hline Sólidos voláteis & $\%(\mathrm{~m} / \mathrm{m})$ & $87,65 \pm 0,15$ \\
\hline Carbono orgânico & $\mathrm{mg} / \mathrm{kg}$ & $404.000 \pm 27.000$ \\
\hline Nitrogênio Total & $\mathrm{mg} / \mathrm{kg}$ & $141.500+4.500$ \\
\hline Nitrogênio, amoniacal & $\mathrm{mg} / \mathrm{kg}$ & $2.314 \pm 282$ \\
\hline Nitrogênio, nitrato-nitrito & $\mathrm{mg} / \mathrm{kg}$ & $44,95 \pm 5,95$ \\
\hline Fósforo & $\mathrm{mg} / \mathrm{kg}$ & $220 \pm 40$ \\
\hline Potássio & $\mathrm{mg} / \mathrm{kg}$ & $68,8 \pm 2,22$ \\
\hline Cálcio & $\mathrm{mg} / \mathrm{kg}$ & $1.303,5+3,5$ \\
\hline Enxofre & $\mathrm{mg} / \mathrm{kg}$ & $11.800 \pm 1.400$ \\
\hline Magnésio & $\mathrm{mg} / \mathrm{kg}$ & $1.900+100$ \\
\hline Boro & $\mathrm{mg} / \mathrm{kg}$ & $\mathrm{ND}^{(1)}$ \\
\hline Cobre & $\mathrm{mg} / \mathrm{kg}$ & $141,1 \pm 65,9$ \\
\hline Ferro & $\mathrm{mg} / \mathrm{kg}$ & $4.239 \pm 1.546$ \\
\hline Manganês & $\mathrm{mg} / \mathrm{kg}$ & $14,7 \pm 7,8$ \\
\hline Molibdênio & $\mathrm{mg} / \mathrm{kg}$ & $\mathrm{ND}^{(1)}$ \\
\hline Zinco & $\mathrm{mg} / \mathrm{kg}$ & $38,8+20,3$ \\
\hline Sódio & $\mathrm{mg} / \mathrm{kg}$ & $18.250,5 \pm 1.980,5$ \\
\hline Alumínio & $\mathrm{mg} / \mathrm{kg}$ & $45,55 \pm 1,35$ \\
\hline Arsênio & $\mathrm{mg} / \mathrm{kg}$ & $2,8+2,8$ \\
\hline Cádmio & $\mathrm{mg} / \mathrm{kg}$ & $\mathrm{ND}^{(1)}$ \\
\hline Chumbo & $\mathrm{mg} / \mathrm{kg}$ & $6,9 \pm 6,9$ \\
\hline Cromo total & $\mathrm{mg} / \mathrm{kg}$ & $23.000 \pm 744$ \\
\hline Mercúrio & $\mathrm{mg} / \mathrm{kg}$ & $\mathrm{ND}^{(1)}$ \\
\hline Níquel & $\mathrm{mg} / \mathrm{kg}$ & $1,85+1,85$ \\
\hline Selênio & $\mathrm{mg} / \mathrm{kg}$ & $\mathrm{ND}^{(1)}$ \\
\hline
\end{tabular}

(1) Não detectadas concentrações menores do que $1,0 \mathrm{mg} / \mathrm{kg}$.

\section{Características físico-químicas}

As características físico-químicas do Adubo Brasileiro estão apresentadas na Tabela 3.

Tabela 3 - Características físico-químicas do Adubo Brasileiro. Compilado pelo autor.

\begin{tabular}{ll}
\hline Aspecto físico & Pó e Grãos \\
Estado físico & Sólido \\
Cor & Preto escuro \\
\hline Odor & Característico do couro \\
\hline
\end{tabular}


Os metais pesados contidos em algumas espécies de adubo são originários do processo industrial, como no caso do couro que é curtido ao cromo para sua conservação, polimento e amaciamento. A pele curtida ao cromo possui grande permeabilidade ao ar e ao vapor (BARROS et al, 2001). A planta retira do solo os elementos minerais indispensáveis para o seu desenvolvimento, conforme a quantidade que é necessária para o seu crescimento. Esses elementos são denominados de macronutrientes (N, P, K, S, Ca, Mg) ou micronutrientes (B, Cl, Co, Cu, Fe, Mn, Mo, Ni, Na, Se, Zn). Além desses, que são essenciais, a planta pode absorver outros minerais não essenciais ( $\mathrm{Al}, \mathrm{Ag}, \mathrm{Cd}$, $\mathrm{Cr}, \mathrm{Hg}, \mathrm{Pb})$.

Os metais pesados não apenas exercem efeitos negativos sobre o crescimento das plantas, a decomposição do material orgânico adicionado ao solo e a mineralização da nitrificação podem ser inibidos em locais contaminados por metais pesados.

Em geral, as plantas têm baixa capacidade de absorver e translocar Cr. A concentração de $\mathrm{Cr}$ em partes de plantas superiores é geralmente na ordem de 0,02 a 0,2 $\mu \mathrm{g} / \mathrm{g}$. Em plantas que crescem no solo, após a aplicação de longo prazo de lama de curtume contendo Cr, este raramente excede alguns $\mu \mathrm{g} / \mathrm{g}$, (JUSTE; MENCH,1992).

Conforme Callegare (2005), o nome deste mineral vem do grego chroma, que significa cor. Ele é integrante do grupo do GTF (Fator de Tolerância da Glicose) e contribui para facilitar, através da síntese de transportadores, a entrada de glicose nas células.

Schwartz e Mertz (1959) demonstraram que o cromo é um elemento essencial em ratos, e uma confirmação posterior (JEEJEBHOY et al, 1977), disse a mesma coisa sobre os humanos. Estudos com uma mulher que havia recebido uma nutrição parenteral (nutrição que se processa fora do tubo gastrintestinal) por cinco anos revelaram que, na ausência do cromo, a paciente tornou-se diabética com marcante intolerância por glicose, baixo peso e condições de pulsação nervosa alterada.

Tratamento com insulina não foi efetivo e somente depois de adicionar 200mg de cromo, na forma de clorido, foi que a paciente aliviou os sintomas de diabetes e não necessitou de nenhum tratamento posterior de insulina. O cromo é atualmente adicionado na rotina básica, nas soluções usadas numa nutrição parenteral total (KHAN et al, 1990).

Várias investigações mostraram que o cromo interage com a glicose e/ou no metabolismo de lipídio em gatos, macacos, porcos da Guiné, coelhos, esquilos, perus, porcos, aves domésticas, terneiros e humanos (ANDERSON, 1988). Os GTF, nos quais o cromo é um componente essencial, são indispensáveis para o açúcar normal, proteínas e para o metabolismo de lipídios. Além disso, o cromo favorece as interações entre a insulina e seus receptores específicos localizados nos órgãos alvos como os músculos e tecidos gordos (MOORANDIAN; MORLEY, 1987).

\section{Conclusão}

Considerando-se sua caracterização econômica e ambiental, bem como se fazendo uma avaliação da energia associada ao resíduo sólido industrial, podemos afirmar que a produção desse adubo trará vários benefícios, pois a degradação dos resíduos sólidos das indústrias de beneficiamento do couro deixará de intensificar a poluição ambiental, isto é, deixará de contribuir para a liberação dos gases produtores do efeito estufa na atmosfera. Além disso, colaborará com a melhoria da saúde pública, diminuindo os riscos e as incertezas ambientais decorrentes de um consumo elevado de energia, o que também é motivo de preocupação nos dias de hoje. São inquietantes, ainda, os riscos de disposições inadequadas dos resíduos em aterros sem controles cuja emissão de gases tóxicos é o maior fator de poluição atmosférica, influenciando diretamente nas mudanças climáticas.

Conclui-se que o aproveitamento energético, através da reciclagem, significa diminuição da carga poluidora lançada no ambiente; contribui com o aumento da vida útil das unidades de tratamento e 
disposição final existentes; colabora com a redução dos impactos decorrentes da produção e uso de energia.

Tendo-se as análises do adubo orgânico do couro bovino, conclui-se que é um produto rico em nitrogênio e carbono. Trará benefício para a agricultura, pois o nitrogênio é requerido em grandes quantidades pelas plantas, mas, ao mesmo tempo, é o nutriente mais universalmente deficiente, pois assim como o carbono, desempenha papéis críticos no crescimento e respiração das plantas devido à sua dupla função como fonte de energia e como estrutura para a construção de outros compostos orgânicos.

\section{Referências}

ABQTIC - ASSOCIAÇÃO BRASILEIRA DOS QUÍMICOS E TÉCNICOS DA INDÚSTRIA DO COURO . Estância Velha, 1996. Anual.

ANDERSON, R. A., 1988. Chromium. In Trace Minerals in Foods. Ed. K Smith, p. 231-247. Marcel Dekker Inc., New York, U.S.A.

BARROS, M. A. S. D.; ARROYO, P. A.; AGULAR, E. F. S.; GARCIA, P. A., 2001. Problemas Ambientales com Soluciones Catalíticas. Ed CYTED. Madrid, España.

CAITANO, L.; DUARTE JUNIOR, L. A., 2004. Estudo Comparativo da Queima de Óleo B.P.F. e de Lenha em Caldeiras - Estudo de caso. Faculdade de Engenharia de Ilha Solteira- FIES e Universidade Estadual Paulista - UNESP. Nova Friburgo.

CAllegAro, J., 2005. Mente Criativa: A Aventura do Cérebro Bem Nutrido. Porto Alegre: Nova Prova. 253p.

CLASS, I. C.; MAIA, R. A. M., 1994. Manual Básico de Resíduos Industriais de Curtumes. Porto Alegre: SENAI, 664p.

GERMANN, H. P., 1985. Chrome Tannage From the Viewpoint of Ecology. Journal of the Society of Leather Trades' Chemists. United Kingdom: v. 79, 82-85.

GUTTERRES, M., 1996. Alternativas Para Destimação do Resíduo de Rebaixamento do Couro WetBlue. Revista do couro, Estância Velha, nº 113, p. 49.

JEEJEBHOY, K. N.; CHU, R. C.; MARLISS, E. B.; GREENBERG, G. R.; BRUCE-ROBERTSON, A., 1977. Chromium Deficiency, Glucose Intolerance and Neuropathy Reversed By Chromium Suplementation in a Petient Receiving Long-term Total Parenteral Nutrition, Am. J. Clin. Nutr. 30, 531-538.

JUSTI, C; MENCH, M., 1992. Long-Term Application of Sewage Sludge and Its Effects on Metal Uptake by Crops. In Biogeochemistry of Trace Metals. Ed DC Adriano. 159-193. Lewis Publishers, Boca Raton.

KHAN, A; BRYDEN, N. A.; POLANSKY, M. M.; ANDERSON, R. A., 1990. Insulin Potentiating Factor and Chromium Content of Selected Foods and Spices, Biol. Trace Element Res. 24, 183-188.

MOORANDIAN, A. D.; MORLEY, J. E., 1987. Microntrient Status in Diabetes Mellitus. J. Clin. Nutr. 45, 877-885.

SCHNEIDER, V. E.; BETTIN, F.; PARISE JUNIOR, F., 2000. Situação das indústrias galvânicas na Região Nordeste do Estado do Rio Grande do Sul quanto ao passivo Ambiental de Lodos de Estações de Tratamento de Efluentes. In: CONGRESSO LATINOAMERICANO DE ENGENHARIA 
SANITÁRIA E AMBIENTAL, 27, 2000, Porto Alegre. Anais... Porto alegre: AIDIS, 1 CD-ROM.

SHEN, T. T., 1995. Industrial Pollution Prevention. New York: Springer.

SHWARTZ, K.; MERTZ, W., 1959. Chromium III and the Glucose Tolerance Factor. Arch. Biochem. Biophys. 85, 292-295.

SPIER, K. F., WESTHAUSER, J. B., 1994. Aproveitamento de Resíduos Sólidos Curtidos ao Cromo. Revista do couro. Estância Velha: ABQTIC. 32-33. 